\title{
The effects of tree characteristics on rainfall interception in urban areas
}

\author{
Byungsun Yang ${ }^{1} \cdot$ Dong Kun Lee ${ }^{2} \cdot$ Han Kyul Heo ${ }^{1} \cdot$ Gregory Biging $^{3}$
}

Received: 2 January 2019 / Revised: 5 June 2019 / Accepted: 10 June 2019 / Published online: 27 June 2019

(c) The Author(s) 2019

\begin{abstract}
Trees in urban areas have significant effects on the urban ecosystem. They can be used to improve the water cycle in urban areas by increasing evaporation and reducing runoff through rainfall interception. Street trees placed in planters on impervious areas reduce runoff by intercepting rainfall and by temporarily storing raindrops on leaves. Therefore, understanding tree canopy geometry and the effect of rainfall interception is important in urban hydrology. In this study, we assessed the effect of tree canopy morphology on rainfall interception using four major street tree species, Sophora japonica L., Ginkgo biloba L., Zelkova serrata (Thunb.) Makino, and Aesculus turbinata Blume, in Seoul, South Korea. We measured throughfall for each tree and also derived three-dimensional data of tree canopy morphology with a terrestrial laser scanner. Tree height, canopy crown width, leaf area index (LAI), leaf area density, mean leaf area, and mean leaf angle were used to determine canopy morphology. The interception rate was mostly affected by the LAI; a higher LAI tended to result in a higher interception rate. Leaf area affected the rainfall interception rate when trees had similar LAIs. These findings on individual tree canopy rainfall interception can help us to understand the importance of rainfall interception in hydrology and for ecological restoration when planning urban green spaces.
\end{abstract}

Keywords Terrestrial laser scanner $\cdot$ Urban water cycle $\cdot$ Leaf area index $\cdot$ Runoff $\cdot$ Tree species

\section{Introduction}

In the urban environment, trees play critical roles by balancing the water cycle and modifying local climate conditions (Guevara-Escobar et al. 2007; Natuhara 2018). Trees are important in urban catchment hydrology because of the interception of rainfall by their canopies. Interception of rainfall by the canopy reduces beneath-canopy throughfall and ultimately reduces runoff in urban catchments. In an urban environment with a high percentage of impervious surfaces, increasing interception and evaporation of rainfall and reducing runoff are crucial to restoring the urban water

Dong Kun Lee

dklee7@snu.ac.kr

1 Interdisciplinary Program in Landscape Architecture, Seoul National University, Seoul 08826, Korea

2 Department of Landscape Architecture and Rural System Engineering, Seoul National University, Seoul 08826, Korea

3 Department of Environmental Science, Policy, and Management, University of California, Berkeley, CA 94720, USA cycle to its natural condition (Livesley et al. 2014). As it is not always feasible to expand the amount of green space in dense urban areas with a high proportion of impervious surface area to increase surface water infiltration and reduce runoff, it is important to select tree species with high rainfall interception to help improve the urban water cycle.

Canopy interception is the amount of rain that is intercepted by a canopy and then evaporates (Xiao et al. 2000). It can be calculated by measuring the difference between gross rainfall and the amount of rain passing through a crown (Huang et al. 2017). As raindrops fall, some drops directly pass through foliage and gaps between branches to reach the ground, which is called "free throughfall." The raindrops intercepted by leaves or branches are temporarily stored on their surfaces (Xiao and McPherson 2016) and eventually evaporate after the rainfall has stopped.

It is important to include trees in an urban environment because of the interception of rain by their canopies. The processes of retaining water temporarily or until it evaporates contribute to improving the urban water cycle. These processes are affected by three main factors: the characteristics of a rainfall event (magnitude, intensity, and duration); 
the characteristics of a canopy (the density and area of leaves, canopy structure); and the weather preceding a rainfall event (Crockford and Richardson 2000).

Previous studies of rainfall interception by tree canopies have mainly been made in forest environments (CarlyleMoses and Gash 2011; Iida et al. 2018; Yousefi et al. 2018). However, little research has been conducted to find out which canopy variables control rainfall interception in an urban environment (Huang et al. 2017; Xiao and McPherson 2011; Zabret et al. 2018). We expect factors affecting canopy interception of rainfall to differ between trees in an urban area and those in a natural forest because of differences in the local environment and because most urban tree canopies are isolated from each other (Livesley et al. 2016). For example, the rainfall storage capacity of a tree canopy is affected by leaf density (Gash et al. 1995) and temperature, wind, shade, and limited space in an urban environment may affect the growth of leaves or stems in comparison to those of trees growing in a forest (Baptista et al. 2018).

Leaf area index (LAI), the projected leaf area per unit ground area (Hosoi and Omasa 2006; Schumacher and Christiansen 2015), is a well-established index used to describe the leaf coverage of a canopy. It is broadly used to quantify the leaf area of a canopy and is used to analyze vegetation dynamics related to rainfall interception (Holder and Gibbes 2017) and radiative transfer (Grau et al. 2017). LAI can be measured in situ or estimated from remote sensing data (Hosoi and Omasa 2006; Sasaki et al. 2008). Recent advances in remote sensing technology have helped the development of diverse methods for the accurate estimation of LAI. High-resolution remote sensing data can be used to estimate to a high level of accuracy both the average LAI and also the spatial distribution of foliage. These data help us to understand tree canopy growth patterns in urban environments that affect rainfall interception (Baptista et al. 2018).

The aim of this study was (1) to explore the factors that affect the amount of rainfall intercepted by four types (species) of urban street trees [Sophora japonica L., Ginkgo biloba L., Zelkova serrata (Thunb.) Makino, and Aesculus turbinata Blume] in Seoul; and (2) to assess the effects of the spatial pattern of LAI on rainfall interception.

\section{Materials and methods}

\section{Study area}

To collect rainfall interception data from different trees, an automatic weather system including an S-RGD-M002 rain gauge (Davis Instruments, Hayward, CA), S-WCF-M003 wind speed and direction smart sensor (Davis Instruments), and HOBO USB micro station data logger (Onset Computer, Bourne, MA) were installed under street trees on Gwanak Campus, Seoul National University (Figs. 1, 2), located in the southern part of Seoul, South Korea. The mean annual precipitation of 30 years (1981-2010) in this region is $1450.5 \mathrm{~mm}$ and the mean annual temperature $12.5^{\circ} \mathrm{C}$ (Korea Meteorological Administration). Sixty-one percent of the precipitation is concentrated in the summer season when temperatures are high. The impervious surface in Seoul increased from $40.0 \%$ in 1962 to $47.7 \%$ in 2010 (Kim et al. 2016); this proportion of impervious surface is detrimental to the urban water cycle.
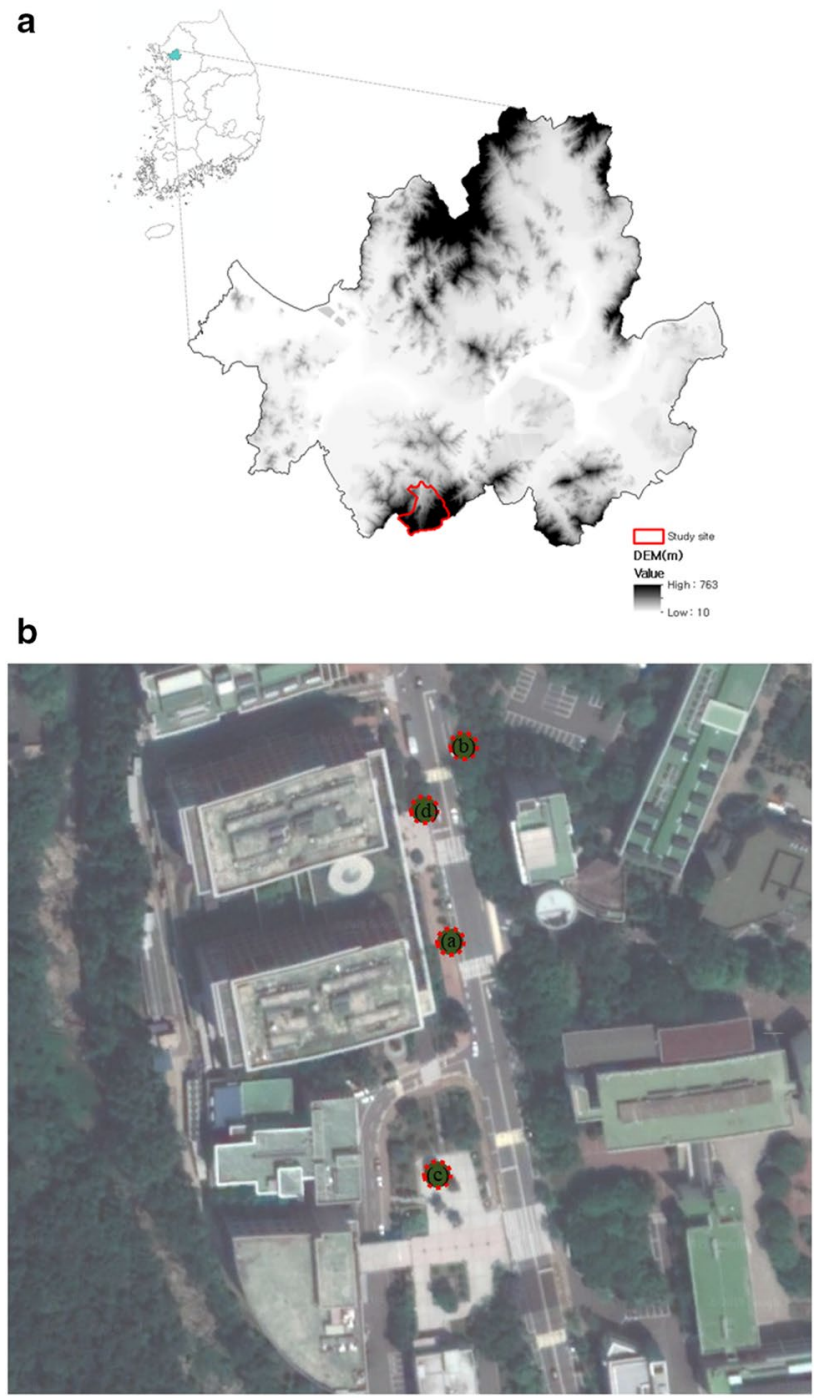

Fig. 1 Top Map of South Korea. Inset Topographic map of Seoul, South Korea; study site outlined in red. Bottom Location of studied trees [Sophora japonica (a), Ginkgo biloba (b), Zelkova serrata (c), and Aesculus turbinata $(d)$ ] on Gwanak Campus, Seoul National University (source: Google Earth) 


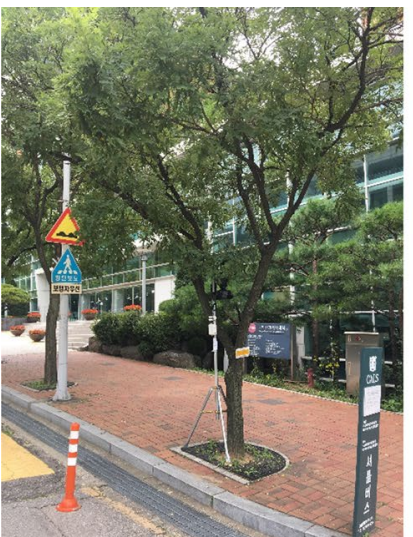

a

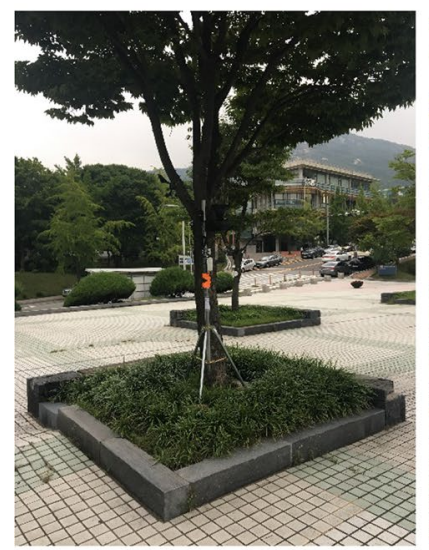

C

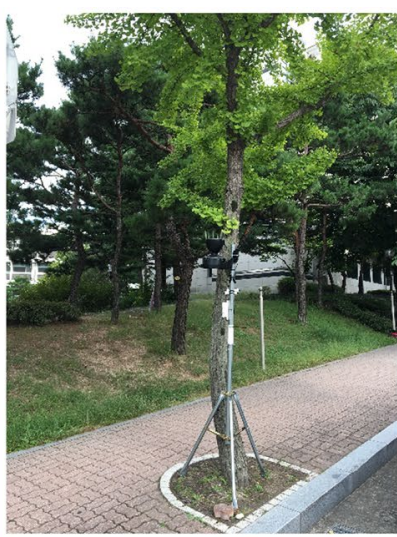

b

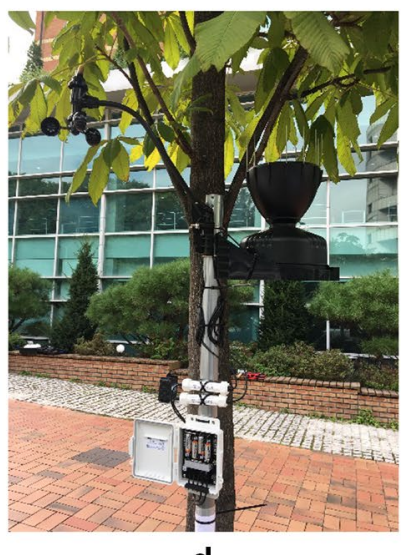

d
Fig. 2a-d Measurement of throughfall under street trees, Gwanak Campus, Seoul National University. a S. japonica, b G. biloba, c Z. serrata, and $\mathbf{d}$ A. turbinata

\section{Data collection}

\section{Throughfall measurement}

Throughfall was measured under the tree canopy of selected street trees on Gwanak Campus from 1 September to 31 November 2018. Eleven rain events were recorded during the measurement period. Minor rain events with precipitation under $5 \mathrm{~mm}$ or rain events with wind speed over $10 \mathrm{~m} \mathrm{~s}^{-1}$ were eliminated from the analysis leaving six rainfall events for analysis. The selected tree species for data collection were Sophora japonica, Ginkgo biloba, Zelkova serrata, and Aesculus turbinata. These species, which have different canopy characteristics, are the most popular street trees in South Korea. Gross precipitation was measured every $1 \mathrm{~min}$ at an open area to eliminate effects by buildings or trees on top of buildings near the street on which the studied trees were located. Wind speed was measured to ensure that only data when the wind speed was under $10 \mathrm{~m} \mathrm{~s}^{-1}$ were used, to reduce the wind effect.

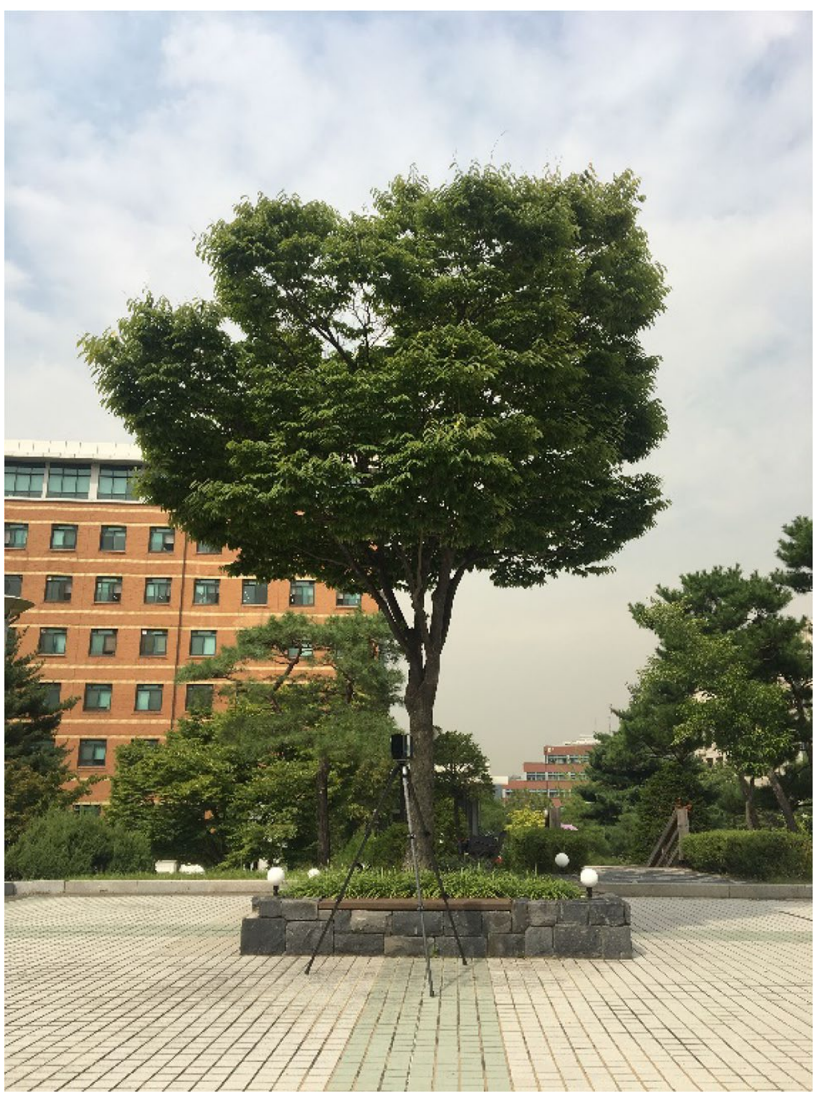

Fig. 3 Scanning Z. serrata using a terrestrial laser scanner. White spheres were placed in multiple locations as reference points used to register scanned images

\section{Measurement of canopy morphological variables}

A terrestrial laser scanner (TLS) was used to measure characteristics for each tree species. TLS, also known as a ground-based light detection and ranging (LiDAR) system, measures an object using a point cloud to create a threedimensional image. Pulses of laser light are directed at a surface and the time it takes for each pulse to bounce back is measured. TLS collects high-resolution data with positional accuracy at the millimeter level in a relatively short time. A Focus 3D-S350 (Faro Technologies, Lake Mary, FL) was used to scan each tree; point spacing of the scanning resolution was $6.1 \mathrm{~mm}$ at $10-\mathrm{m}$ distance. Point clouds scanned from at least eight points were registered using CloudCompare [open source software (Baptista et al. 2018)] based on spheres placed in strategic locations prior to scanning (Fig. 3). The spheres are used to "tie" the image points taken from multiple locations to create one complete image of a single tree canopy. Tree data were cropped and noise data were removed using CloudCompare noise filter (Fig. 4).

We obtained foliage data from the point cloud data of the tree canopies to calculate LAI using MATLAB. Average 


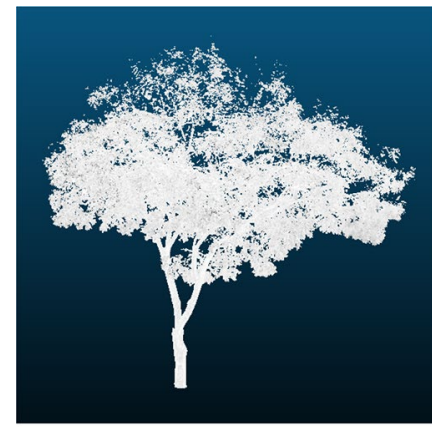

a

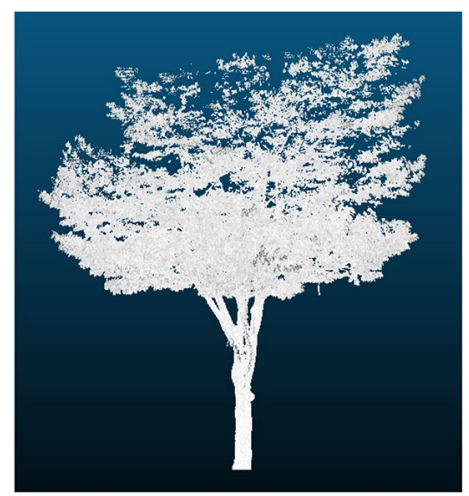

C

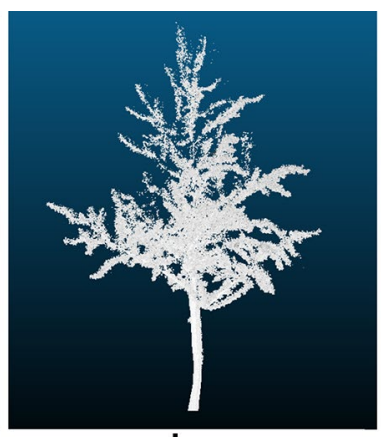

b

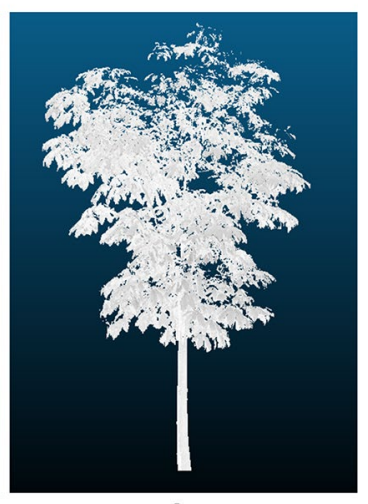

d
Fig. 4a-d Point cloud data of four trees. a S. japonica, b G. biloba, c $Z$. serrata, and $\mathbf{d} A$. turbinata

LAI of total tree canopy was derived as well as the central section LAI of the canopy by using point clouds at $1-\mathrm{m}$ radius from the trunk. Other canopy properties affect interception, such as mean leaf area and leaf area density (LAD), which affect the capacity of a tree to store rainfall (Baptista et al. 2018; Holder 2013; Holder and Gibbes 2017). Leaf angle, which affects water droplet retention (Holder 2012; Xiao et al. 2002), and tree height and width of canopy crown, which affect the total storage capacity of the tree canopy (Baptista et al. 2018; Xiao and McPherson 2011) were also derived using point cloud data. To calculate the mean leaf area and leaf angle, the tree canopy was divided into three sections vertically and horizontally. Ten leaves were collected from each section, thus 90 leaves were used to calculate the mean leaf area and angle of each tree using MATLAB. Leaf angle was calculated by using the least squares method to find the plane that fit the leaf plane (Wei et al. 2016; Zhao et al. 2015). Each plane was calculated by using the normal vector of the base plane and fitted plane of the leaf (Hosoi and Omasa 2015; Li et al. 2018). The cloud point of each leaf was collected manually using CloudCompare and the calculation of leaf angle was coded in MATLAB. LAD was calculated by dividing leaf point cloud data into sections through voxelization ( $\mathrm{Li}$ et al. 2018). Each 0.1-m voxel was the basic unit and the point cloud of leaves was used for LAD calculation. In addition, tree height and width of canopy crown were derived by using the maximum, minimum tree point cloud data in MATLAB. After retrieving canopy morphological variables, we used one-way ANOVA for LAI, LAD, leaf angle, tree height and width of canopy crown with rainfall interception rate.

\section{Results}

\section{Throughfall}

The gross precipitation ranged from 5.8 to $71.6 \mathrm{~mm}$ and rainfall intensity from 0.46 to $5.5 \mathrm{~mm} \mathrm{~h}^{-1}$ (Table 1). Throughfall for each tree species varied depending on the gross precipitation and rainfall intensity.

\section{Canopy morphology}

The radial LAI distribution showed a remarkable decrease from the center of the crown towards the edge of the crown. The highest LAI for all four tree species was typically in the range of $0.25-0.75 \mathrm{~m}$ from the center of the crown (Fig. 5). A. turbinata showed the highest LAI, 9, whereas the other species had an LAI of approximately 7 . All trees showed the same overall decreasing trend of radial LAI. However, $G$. biloba showed a more gradual decrease in LAI with distance from the center of the tree crown up to $0.75 \mathrm{~m}$ compared to the other tree species.

Table 1 Throughfall for each tree and interception rate

\begin{tabular}{lcrrrrr}
\hline Date & $\begin{array}{l}\text { Sophora japonica } \\
\text { Interception rate (\%) }\end{array}$ & Ginkgo biloba & Zelkova serrata & Aesculus turbinata & $\begin{array}{c}\text { Gross pre- } \\
\text { cipitation }\end{array}$ & $\begin{array}{l}\text { Rainfall inten- } \\
\text { sity }\left(\mathrm{mm} \mathrm{h}^{-1}\right)\end{array}$ \\
\hline 3 September 2018 & $28.2(20.34)$ & $18.2(48.59)$ & $32.0(9.60)$ & $26.2(25.99)$ & 35.4 & 5.0 \\
20 September 2018 & $3.0(57.14)$ & $2.6(62.86)$ & $5.2(25.71)$ & $4.6(34.29)$ & 7.0 & 0.4 \\
21 September 2018 & $10.0(48.98)$ & $7.0(64.29)$ & $13.6(30.61)$ & $11.6(40.82)$ & 19.6 & 1.6 \\
5 October 2018 & $17.6(41.72)$ & $15.6(48.34)$ & $25.2(16.56)$ & $20.0(33.77)$ & 30.2 & 5.0 \\
6 October 2018 & $50.6(29.33)$ & $42.4(40.78)$ & $57.0(20.39)$ & $51.6(27.93)$ & 51.6 & 5.5 \\
10 October 2018 & $4.8(17.24)$ & $1.0(82.76)$ & $4.6(20.69)$ & $4.6(20.69)$ & 5.8 & 2.9 \\
\hline
\end{tabular}


Fig. 5 Radial distribution of leaf area index ( $L A I)$ for each tree species. A. turbinata had the highest LAI; the other trees had similar LAIs

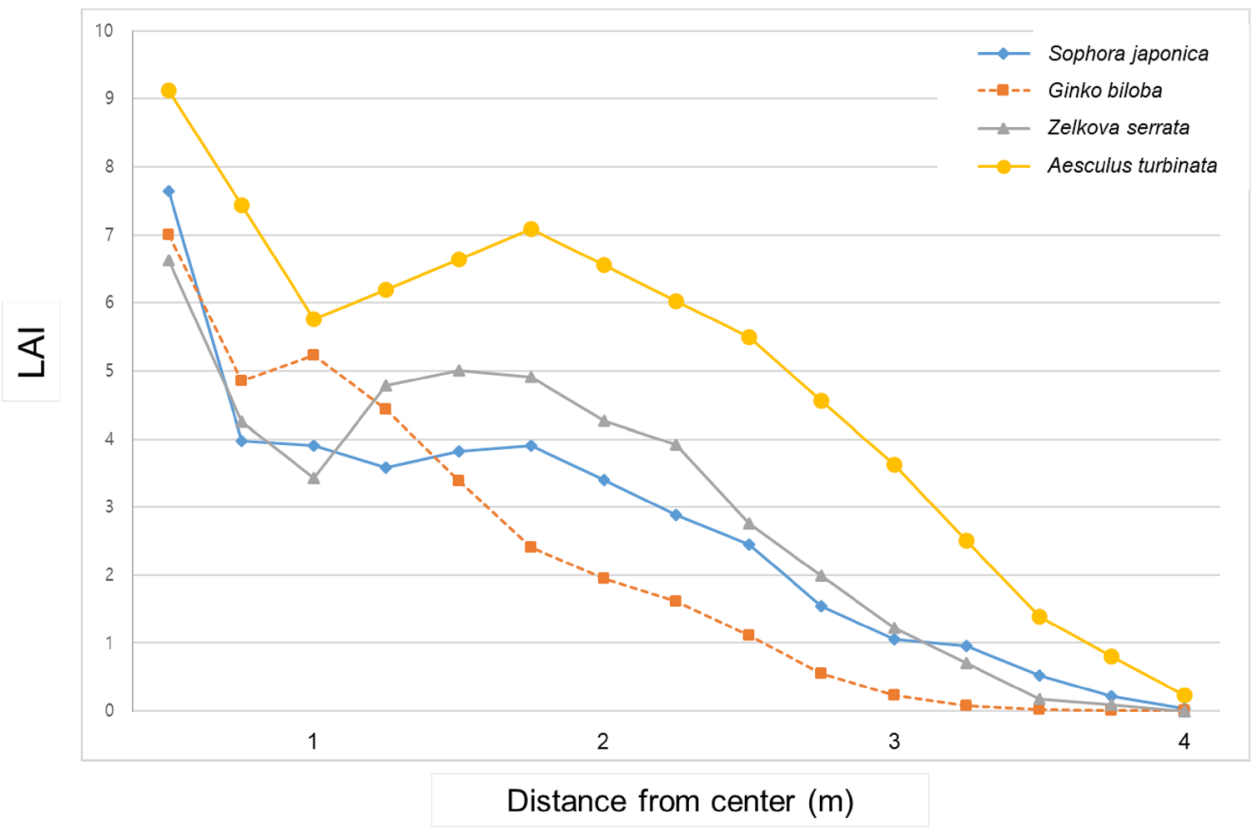

The highest vertical LAIs were in the middle or middlehigh section of $S$. japonica, Z. serrata, and A. turbinata crowns, and low section of the G. biloba crown (skewness of $0.503,0.485,0.024$, and 0.949, respectively) (Fig. 6). $Z$. serrata had the highest LAI, 0.4-0.6 at a tree height of 2.5-3.5 m. G. biloba had the lowest LAI, which did not exceed 0.2 for all measured positions.

The ratio of tree height to width of canopy was used to indicate tree shape. A. turbinata had the highest ratio, 1.60, while G. biloba, Z. serrata, and S. japonica had ratios of $1.38,1.03$, and 0.84 , respectively. The mean leaf area was highest for A. turbinata at approximately $1951 \mathrm{~mm}^{2}$, while those of Z. serrata, S. japonica, and G. biloba were approximately $1365 \mathrm{~mm}^{2}, 933 \mathrm{~mm}^{2}$, and $561 \mathrm{~mm}^{2}$, respectively (Table 2). The mean leaf angle of $Z$. serrata was lowest at approximately $38^{\circ}$, while those of the other species were approximately $44^{\circ}$ or more. The average LAD was similar between for the four trees, i.e., $0.13-0.16 \mathrm{~m}^{2} \mathrm{~m}^{-3}$.

\section{Influence of tree morphology on rainfall interception}

Mean interception rate during six rainfall events varied between the tree species. G. biloba had the highest mean rainfall interception rate at $57.93 \%$, while those of $S$. japonica, A. turbinata, and Z. serrata were 35.79, 30.58, and $20.59 \%$, respectively. One-way ANOVA showed that tree canopy interception rate significantly differed between rainfall events and with tree canopy characteristics (Table 3). The data confirmed that LAI $\left(P=7.61 e^{-05}\right)$, LAI of the central section of the canopy $(P=0.002)$, and mean leaf area $(P=0.004)$ significantly differed and that rainfall intensity was marginally significantly different $(P=0.071)$ across all the analyses when explaining the variation in rainfall interception by the tree canopies. There was no significant correlation $(P>0.01)$ between rainfall interception rate and tree canopy morphological characteristics such as leaf angle, LAD, and tree height to width ratio.

\section{Discussion}

The LAI of the central section of the tree canopy is the most influential canopy characteristic for rainfall interception rate. $G$. biloba has the highest interception rate and LAI at the canopy center, and also the highest number of vertical layers with an LAI over 0.4 (Table 2). For trees with relatively similar LAIs such as the four species investigated, the difference in rainfall interception rate can be explained by the mean leaf area. S. japonica and Z. serrata had a similar LAI of approximately 5, whereas G. biloba and A. turbinata had a similar LAI of 7.0 and 6.3, respectively. The mean leaf areas of S. japonica and Z. serrata were $933 \mathrm{~mm}^{2}$ and $1365 \mathrm{~mm}^{2}$, and those of G. biloba and A. turbinata were $561 \mathrm{~mm}^{2}$ and $1951 \mathrm{~mm}^{2}$, respectively. These data indicate that smaller leaves are more effective in intercepting rainfall than larger leaves.

The relationship between LAI and rainfall interception in the present study is consistent with that of previous studies on urban street trees (Holder and Gibbes 2017; Huang et al. 2017). We also discovered that the mean leaf area significantly affects the rainfall interception rate. In addition, we showed that rainfall intensity is relevant to rainfall interception. The canopies intercepted more rain 
Fig. 6a-d Vertical distribution of LAI. a $S$. japonica, b $G$. biloba, $\mathbf{c} Z$. serrata, and $\mathbf{d} A$. turbinata
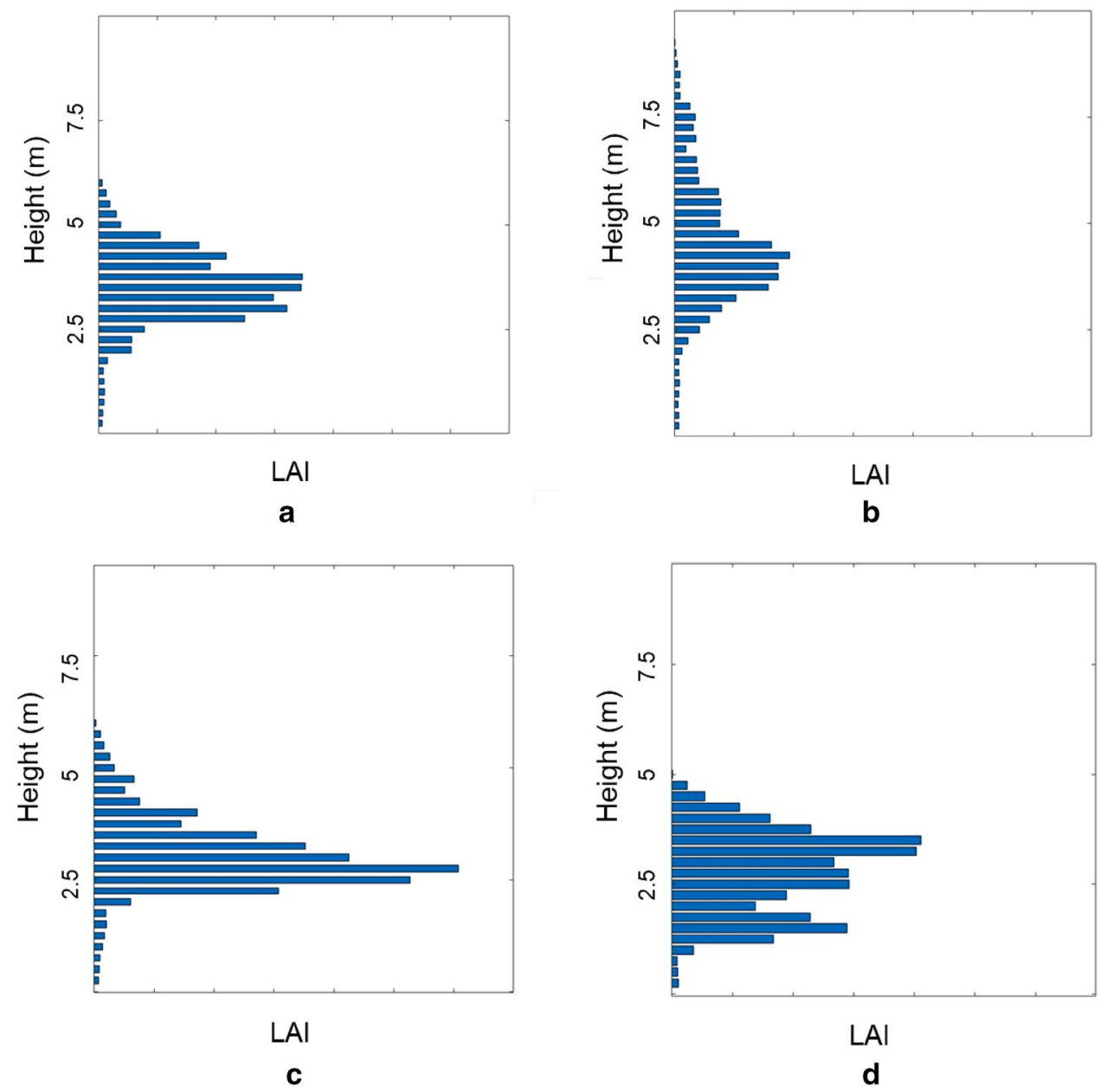

Table 2 Canopy rainfall interception rate and other canopy variables for each tree

\begin{tabular}{lllll}
\hline & S. japonica & G. biloba & Z. serrata & A. turbinata \\
\hline Mean interception rate and range $(\%)$ & $35.79(17.24-57.14)$ & $57.93(40.78-82.76)$ & $20.59(9.60-30.61)$ & $30.58(20.69-40.82)$ \\
Tree height/width of crown & 0.84 & 1.38 & 1.03 & 1.60 \\
Mean leaf area $\left(\mathrm{mm}^{2}\right)$ & 933 & 561 & 1365 & 1951 \\
Mean leaf angle $\left({ }^{\circ}\right)$ & 46.21 & 47.68 & 38.95 & 44.06 \\
LAD $\left(\mathrm{m}^{2} \mathrm{~m}^{-3}\right)$ & 0.13 & 0.16 & 0.14 & 0.16 \\
Leaf area index (LAI) & 2.61 & 1.98 & 3.28 & 3.37 \\
LAI of central section & 5.11 & 7.02 & 5.02 & 6.37 \\
\hline
\end{tabular}

during small storm events, which scatter rain rather than increase rainfall intensity (Barbier et al. 2009; Livesley et al. 2014). The differences in rainfall interception rates between the tree species were larger for rainfall of low intensity, since small rainfall events were not sufficient to totally saturate the tree canopies that had a large storage capacity (Huang et al. 2017). Thus, trees with a large rainfall storage capacity were not saturated while trees with a small storage capacity were. This indicates the importance of the spatial distribution of a tree canopy when estimating its total rainfall interception. Traditionally, rainfall interception by a tree canopy is estimated by using the average LAI of the whole tree canopy (Fathizadeh et al. 2018; Liu et al. 2018), even though the saturation of certain leaves or a canopy section can affect spatial and total rainfall interception rates. By using the recently developed TLS and point cloud techniques (Hosoi and Omasa 2006), it is possible to estimate the spatial distribution of LAI in a tree canopy and the effect of this on urban ecology at a finer scale. 
Table 3 One-way ANOVA of rainfall interception

\begin{tabular}{llrrrrr}
\hline & Source of variation & $d f$ & SS & MS & $F$ & $P$ \\
\hline Rainfall intensity & Between group & 1 & 1042 & 1042 & 3.57 & 0.071 \\
& Within group & 22 & 6412 & 291 & & \\
& Total & 23 & 6921 & & & \\
Mean leaf area & Between group & 1 & 2372 & 2372 & 10.27 & 0.004 \\
& Within group & 22 & 5083 & 231 & & \\
LAI & Total & 23 & 7455 & & & \\
& Between group & 1 & 3843 & 3843 & 23.41 & $7.61 . \mathrm{E}^{-05}$ \\
& Within group & 22 & 3612 & 164 & & \\
LAI central section & Total & 23 & 7455 & & & \\
& Between group & 1 & 2664 & 2663 & 12.23 & 0.002 \\
& Within group & 22 & 4791 & 217 & & \\
& Total & 23 & 7455 & & & \\
\hline
\end{tabular}

It is difficult to quantify rainfall interception for every tree of interest, thus it is usually estimated indirectly by using LAI as a coefficient (Pereira et al. 2016; Su et al. 2016). However, the aim of this research was not to classify and generalize about each studied tree species by collecting a large amount of data (Holder and Gibbes 2017). Instead, in this study, tree species with different canopy characteristics were selected to assess which ones affect rainfall interception (Baptista et al. 2018; Holder 2013; Livesley et al. 2014; Xiao and McPherson 2011). Research designed to use data in the Gash model (Pereira et al. 2016; Su et al. 2016) needs to obtain a certain amount of measured data for generalizations. However, as the present study was not designed to examine the general characteristics of tree species but the characteristics of individual trees, we chose one tree of each of the four species assessed and measured their rainfall interception. To make generalizations and extrapolate the results to other trees, more numerous measurements of the species of interest are required.

\section{Conclusion}

We assessed tree canopy morphological variables that affect rainfall interception rate and demonstrated the importance of the spatial distribution of the canopy LAI. Tree species with a higher LAI had a higher rainfall interception rate. Where tree species had similar LAI, the rainfall interception rate was affected by average leaf area. Rainfall intensity and total intercepted precipitation varied for our study trees, which are the major street tree species in Seoul. The trees studied had average rainfall interception rates of approximately $20-60 \%$, with higher rates occurring during less intense rainfall. It should be noted that, since throughfall data were measured in the central section of the crown, interception rate may have been overestimated. To overcome this limitation, the LAI was derived separately and compared with the average LAI of the whole tree.
Acknowledgements This subject is supported by the Korea Ministry of Environment (MOE, Project No. 2016000210004) as "Public Technology Program based on Environmental Policy" and by the BK 21 Plus Project in 2018 (Seoul National University Interdisciplinary Program in Landscape Architecture, Global Leadership Program Toward Innovative Green Infrastructure).

Open Access This article is distributed under the terms of the Creative Commons Attribution 4.0 International License (http://creativecommons.org/licenses/by/4.0/), which permits unrestricted use, distribution, and reproduction in any medium, provided you give appropriate credit to the original author(s) and the source, provide a link to the Creative Commons license, and indicate if changes were made.

\section{References}

Baptista MD, Livesley SJ, Parmehr EG et al (2018) Variation in leaf area density drives the rainfall storage capacity of individual urban tree species. Hydrol Process 32:3729-3740

Barbier S, Balandier P, Gosselin F (2009) Influence of several tree traits on rainfall partitioning in temperate and boreal forests: a review. Ann For Sci 66:1-11

Carlyle-Moses DE, Gash JHC (2011) Forest hydrology and biogeochemistry. Ecol Stud 216:407-423

Crockford RH, Richardson DP (2000) Partitioning of rainfall into throughfall, stemflow and interception: effect of forest type, ground cover and climate. Hydrol Process 14:2903-2920

Fathizadeh O, Hosseini SM, Keim RF, Boloorani AD (2018) A seasonal evaluation of the reformulated Gash interception model for semi-arid deciduous oak forest stands. For Ecol Manage 409:601-613

Gash JHC, Lloyd CR, Lachaud G (1995) Estimating sparse forest rainfall interception with an analytical model. J Hydrol 170:79-86

Grau E, Durrieu S, Fournier R et al (2017) Estimation of 3D vegetation density with terrestrial laser scanning data using voxels. A sensitivity analysis of influencing parameters. Remote Sens Environ 191:373-388

Guevara-Escobar A, González-Sosa E, Véliz-Chávez C et al (2007) Rainfall interception and distribution patterns of gross precipitation around an isolated Ficus benjamina tree in an urban area. J Hydrol 333:532-541 
Holder CD (2012) The relationship between leaf hydrophobicity, water droplet retention, and leaf angle of common species in a semiarid region of the western United States. Agric For Meteorol 152:11-16

Holder CD (2013) Effects of leaf hydrophobicity and water droplet retention on canopy storage capacity. Ecohydrology 6:483-490

Holder CD, Gibbes C (2017) Influence of leaf and canopy characteristics on rainfall interception and urban hydrology. Hydrol Sci J 62:182-190

Hosoi F, Omasa K (2006) Voxel-based 3-D modeling of individual trees for estimating leaf area density using. IEEE Trans Geosci Remote Sens 44:3610-3618

Hosoi F, Omasa K (2015) Estimating leaf inclination angle distribution of broad-leaved trees in each part of the canopies by a highresolution portable scanning lidar. J Agric Meteorol 71:136-141

Huang JY, Black TA, Jassal RS, Lavkulich LML (2017) Modelling rainfall interception by urban trees. Can Water Resour J 42:336-348

Iida S, Levia DF, Nanko K et al (2018) Correction of canopy interception loss measurements in temperate forests: a comparison of necessary adjustments among three different rain gauges based on a dynamic calibration procedure. J Hydrometeorol 19:547-553

Kim H, Lee DK, Sung S (2016) Effect of urban green spaces and flooded area type on flooding probability. Sustain 8:134-151

Li Y, Su Y, Hu T et al (2018) Retrieving 2-D leaf angle distributions for deciduous trees from terrestrial laser scanner data. IEEE Trans Geosci Remote Sens 56:4945-4955

Liu Z, Wang Y, Tian A et al (2018) Characteristics of canopy interception and its simulation with a revised Gash model for a larch plantation in the Liupan Mountains, China. J For Res 29:187-198

Livesley SJ, Baudinette B, Glover D (2014) Rainfall interception and stem flow by eucalypt street trees-the impacts of canopy density and bark type. Urban For Urban Green 13:192-197

Livesley SJ, McPherson GM, Calfapietra C (2016) The urban forest and ecosystem services: impacts on urban water, heat, and pollution cycles at the tree, street, and city scale. J Environ Qual 45:119-124

Natuhara Y (2018) Green infrastructure: innovative use of indigenous ecosystems and knowledge. Landsc Ecol Eng 14:187-192

Pereira FL, Valente F, David JS et al (2016) Rainfall interception modelling: is the wet bulb approach adequate to estimate mean evaporation rate from wet/saturated canopies in all forest types? J Hydrol 534:606-615

Sasaki T, Imanishi J, Ioki K et al (2008) Estimation of leaf area index and canopy openness in broad-leaved forest using an airborne laser scanner in comparison with high-resolution near-infrared digital photography. Landsc Ecol Eng 4:47-55

Schumacher J, Christiansen JR (2015) Forest canopy water fluxes can be estimated using canopy structure metrics derived from airborne light detection and ranging (LiDAR). Agric For Meteorol 203:131-141

Su L, Zhao C, Xu W, Xie Z (2016) Modelling interception loss using the revised Gash model: a case study in a mixed evergreen and deciduous broadleaved forest in China. Ecohydrology 9:1580-1589

Wei T, Lin Y, Yan L, Zhang L (2016) Tree species classification based on stem-related feature parameters derived from static terrestrial laser scanning data. Int J Remote Sens 37:4420-4440

Xiao Q, McPherson GG (2011) Rainfall interception of three trees in Oakland, California. Urban Ecosyst 14:755-769

Xiao Q, McPherson EG (2016) Surface water storage capacity of twenty tree species in Davis, California. J Environ Qual 45:188-198

Xiao Q, McPherson EG, Ustin SL, Grismer ME (2000) A new approach to modeling tree rainfall interception. J Geophys Res Atmos 105:29173-29188

Xiao Q, Simpson JR, McPherson EG et al (2002) Winter rainfall interception by two mature open-grown trees in Davis, California. Hydrol Process 14:763-784

Yousefi S, Sadeghi SH, Mirzaee S et al (2018) Spatio-temporal variation of throughfall in a hyrcanian plain forest stand in northern Iran. J Hydrol Hydromech 66:97-106

Zabret K, Rakovec J, Šraj M (2018) Influence of meteorological variables on rainfall partitioning for deciduous and coniferous tree species in urban area. J Hydrol 558:29-41

Zhao K, García M, Liu S et al (2015) Terrestrial lidar remote sensing of forests: maximum likelihood estimates of canopy profile, leaf area index, and leaf angle distribution. Agric For Meteorol 209-210:100-113 